\title{
Leadership for Organizational Effectiveness in Academic Sector to Maintain the Quality of Education
}

\author{
Kedar Dulal \\ School of Education, Kathmandu University, Hattiban, Lalitpur, Nepal \\ Email address: \\ kedardulal@gmail.com
}

\section{To cite this article:}

Kedar Dulal. Leadership for Organizational Effectiveness in Academic Sector to Maintain the Quality of Education. Teacher Education and Curriculum Studies. Vol. 2, No. 4, 2017, pp. 52-60. doi: 10.11648/j.tecs.20170204.13

Received: June 13, 2017; Accepted: July 4, 2017; Published: July 31, 2017

\begin{abstract}
The ideas planned by Total Quality Management (TQM) organizer, W. Edwards Deming, have been recommended as a reason for accomplishing greatness in schools. It is a chance to conceptualize a precise change for schools. In this article to examine the system for changing schools utilizing Deming's 14 TQM standards. Add up to Quality Management (TQM) is perceived as a critical administration rationality and is broadly utilized as a part of school. It has been utilized effectively in the advancement and procurement of frameworks. In the course of the most recent couple of years, TQM has been connected in the training business. The vast majority of the applications have been in the authoritative side of the foundations, however a few schools have connected TQM to educational modules advancement. In this paper, the standards of TQM are depicted with an accentuation on the significance of recognizing the client and breaking down the procedures. The 14 Points of Dr. W. Edwards Deming, which shape a structure for the execution of the TQM, are independently connected to the scholastic condition in light of the experience picked up at the education sector. The key focuses for the change of training are logical and innovative improvement, social changes and authoritative changes. Instruction proficiency and achievement don't depend just on amount however also on quality. The quality pointer arrangement of instruction, and additionally the criteria identified with the quality markers help schools to distinguish the significant ranges of their exercises their own favorable circumstances, impediments and advancement openings.
\end{abstract}

Keywords: Quality, Quality Management, Total Quality Management, Educational System, Quality Indicators, Organizational Effectiveness

\section{Introduction}

TQM as an administration demonstrate, with its accentuation on authority, technique, collaboration, thorough examination and self-appraisal, has an all inclusive message. TQM in training has as its message each understudy has worth and requests the most ideal possibility in life. Add up to - comprised of the entire, Quality - level of magnificence an item or administration gives, Management - act, workmanship or way of arranging, controlling, coordinating. Accordingly, TQM is the specialty of dealing with the entire to accomplish greatness. Add up to Quality Management implies that the association's way of life is characterized by and bolsters the steady fulfillment of consumer loyalty through a coordinated arrangement of instruments, methods, and preparing. This includes the persistent change of authoritative procedures, bringing about amazing items and administrations. The objective of the aggregate quality administration "Do the correct things right the first run through, unfailingly".

TQM is an orderly way to deal with instruction change in light of the rationality of W. Edwards Deming (2000). Deming's reasoning gives a structure that can incorporate numerous positive improvements in instruction, for example, term-educating, site-based administration, agreeable learning, and results based training.

\section{Importance of TQM}

Responsibility and comprehension from representatives : it is vital to guarantee that all representatives inside your association think about the Total Quality Management (TQM) arrangements and make them a major some portion of their work. Your representatives ought to know your 
corporate objectives and perceive the significance of these objectives to the general accomplishment of your association. Representatives need to comprehend what is normal from them and why. It might seem like an easy decision however time after time this is not driven home by administration. At the point when workers comprehend and share an indistinguishable vision from administration a universe of potential is unleashed. On the off chance that they are oblivious, responsibility is missing and arrangements won't be effectively sent.

\subsection{Quality Improvement Culture}

The hierarchical culture should be modernized on a persistent premise to support representative input. Your representatives are brimming with important information grasp it! Tune in to those executing the procedures that keep your business moving day by day. On the off chance that workers have a thought on the most proficient method to enhance operations, they have to know administration regards their thoughts or they won't share.

\subsection{Continuous Improvement in Process}

There is no stopping. In the event that you are not advancing, you are moving in reverse. Add up to Quality Management (TQM) is a constant procedure and not a program. This requires consistent change in all the related arrangements, strategies and controls set up by administration. Do your exploration. Keep your ear to the market and attempt to routinely reconsider all parts of your operation. There ought to be a consistent push to enhance capability - which will bring about steady degrees for development (regardless of the possibility that a few upgrades are little).

\subsection{Focus on Customer Requirements}

In today's market, clients require and expect idealize products and ventures with zero imperfections. Concentrating on client necessities is critical to long haul survival and basic keeping in mind the end goal to fabricate associations with clients. Individuals work together in view of feeling. Contenders will dependably be a hazard. Keep your clients close and cheerful. Ensure exact necessities of all clients are reported and comprehended by everybody that touches the record.

\subsection{Effective Control}

It is basic to screen and measure the execution of the business. It's anything but difficult to overlook how often in a year a representative does not comply with a controlled system or how frequently a bit of hardware was down because of impromptu upkeep. On the off chance that strict documentation is kept up, you will have the capacity to impartially evaluate territories for development and center your endeavors where they will give the best return of both your time and money related assets. (Napierala, 2017).

\section{Principles of TQM}

\subsection{Customer Centric Approach}

Buyers are a definitive judge to decide if items or administrations are of unrivaled quality or not. Regardless of what number of assets are pooled in preparing workers, redesigning machines and PCs, consolidating quality plan process and norms, bringing new innovation, and so on.; by the day's end, the clients have the last say in judging your organization. Organizations must make sure to execute TQM over all fronts remembering the clients.

\subsubsection{Employee Involvement}

Guaranteeing complete representative contribution in accomplishing objectives and business goals will prompt worker strengthening and dynamic support from the workers in basic leadership and tending to quality related issues. Representative strengthening and association can be expanded by making the workspace more open and without dread.

\subsubsection{Continual Improvement}

A noteworthy segment of TQM is ceaseless change. Consistent change will prompt enhanced and higher quality procedures. Nonstop change will guarantee organizations will discover new ways and strategies in delivering better quality items, generation, be more focused, and in addition surpass client desires.

\subsection{Strategic Approach to Improvement}

Organizations must receive a vital approach towards quality change to accomplish their objectives, vision, and mission. A vital arrangement is exceptionally important to guarantee quality turns into the center part of all business forms.

\subsubsection{Integrated System}

Organizations contain different divisions with various usefulness purposes. These functionalities are interconnected with different level procedures TQM concentrates on. Everybody in the organization ought to have an exhaustive comprehension of the quality arrangements, models, destinations, and critical procedures. It is essential to advance a quality work culture as it accomplishes greatness and outperform client desires. A coordinated framework guarantees persistent change and enables organizations to accomplish an aggressive edge.

\subsubsection{Decision Making}

Information from the execution estimation of procedures shows the present wellbeing of the organization. For productive TQM, organizations should gather and break down information to enhance quality, basic leadership precision, and gauges. The basic leadership must be factually and situational situated with a specific end goal to maintain a strategic distance from any space for passionate based choices. 


\subsubsection{Communications}

Correspondence assumes a vital part in TQM as it rouses representatives and enhance their confidence amid routine day by day operations. Representatives should be included however much as could be expected in the everyday operations and basic leadership procedure to truly give them a feeling of strengthening. This makes nature of accomplishment and solidarity and drives the outcomes the TQM procedure can accomplish.

It requires massive endeavors, time, mettle, and persistence to effectively actualize TQM. Organizations effectively actualizing TQM can witness enhanced quality over every real procedure and divisions, higher client maintenance, higher income because of enhanced deals, and worldwide brand acknowledgment. (Etech", 2017)

\section{Eight Element of TQM}

TQM has been coined to describe a philosophy that makes quality the driving force behind leadership, design, planning, and improvement initiatives. For this, TQM requires the help of those eight key elements. These elements can be divided into four groups according to their

\subsection{Foundation}

TQM is based on an establishment of morals, respectability and trust. It cultivates openness, decency and earnestness and permits inclusion by everybody. This is the way to opening a definitive capability of TQM. These three components move together, be that as it may, every component offers something else to the TQM idea.

\subsubsection{Morals}

Ethics is the teach worried with great and terrible in any circumstance. It is a two-faceted subject spoken to by hierarchical and individual morals. Authoritative morals build up a business code of morals that blueprints rules that all representatives are to hold fast to in the execution of their work. Singular morals incorporate individual rights or wrongs.

\subsubsection{Respectability}

Integrity suggests trustworthiness, ethics, qualities, reasonableness, and adherence to the realities and truthfulness. The trademark is the thing that clients (inner or outside) anticipate that and merit will get. Individuals see the inverse of respectability as trickery. TQM won't work in an air of guile.

\subsubsection{Trust}

Trust is a by-result of uprightness and moral lead. Without trust, the structure of TQM can't be assembled. Trust cultivates full interest of all individuals. It permits strengthening that energizes pride proprietorship and it supports responsibility. It permits basic leadership at suitable levels in the association, encourages singular hazard taking for constant change and guarantees that estimations concentrate on change of process and are not used to fight individuals. Trust is fundamental to guarantee consumer loyalty. Along these lines, trust constructs the agreeable condition fundamental for TQM.

\subsection{Building Bricks}

Basing on the solid establishment of trust, morals and respectability, blocks are set to achieve the top of acknowledgment. It incorporates:

Preparing: Training is critical for workers to be exceedingly profitable. Managers are exclusively in charge of actualizing TQM inside their areas of expertise, and showing their workers the methods of insight of TQM. Preparing that workers require are relational aptitudes, the capacity to work inside groups, critical thinking, basic leadership, work administration execution investigation and change, business financial aspects and specialized abilities. Amid the creation and development of TQM, workers are prepared with the goal that they can wind up noticeably successful representatives for the organization.

\subsubsection{Cooperation}

To wind up plainly fruitful in business, collaboration is likewise a key component of TQM. With the utilization of groups, the business will get speedier and better answers for issues. Groups likewise give more perpetual upgrades in procedures and operations. In groups, individuals fondle more happy with bringing issues that may happen, and can get assistance from different specialists to discover an answer and established. There are fundamentally three sorts of groups that TQM associations receive:

\subsubsection{Quality Change Groups or Greatness Groups (QITs)}

These are brief groups with the reason for managing particular issues that frequently repeat. These groups are set up for time of three to twelve months.

Critical thinking groups (PSTs): These are brief groups to tackle certain issues and furthermore to recognize and defeat reasons for issues. They by and large last from one week to three months.

\subsubsection{Regular Work Groups (NWTs)}

These groups comprise of little gatherings of talented specialists who share assignments and obligations. These groups utilize ideas, for example, worker inclusion groups, self-overseeing groups and quality circles. These groups for the most part work for one to two hours seven days encourages full interest of all individuals. It permits strengthening that supports pride possession and it empowers responsibility. It permits basic leadership at proper levels in the association, encourages singular hazard taking for constant change and guarantees that estimations concentrate on change of process and are not used to battle individuals. Trust is fundamental to guarantee consumer loyalty. Thus, trust manufactures the helpful condition fundamental for TQM.

\subsection{Leadership}

It is perhaps the most essential component in TQM. It 
shows up wherever in the association. Initiative in TQM requires the chief to give a rousing vision, make key headings that are comprehended by all and to impart values that guide subordinates. For TQM to be fruitful in the business, the manager must be focused on driving his workers. A chief must comprehend TQM, have faith in it and afterward exhibit their conviction and duty through their every day practices of TQM. The boss ensures that procedures, methods of insight, qualities and objectives are transmitted down all through the association to give center, clearness, and course. A key point is that TQM must be presented and driven by top administration. Duty and individual association are required from top administration in making and sending clear quality esteems and objectives predictable with the targets of the organization and in making and conveying very much characterized frameworks, techniques and execution measures for accomplishing those objectives.

\subsection{Binding Mortar}

Correspondence ties everything together. Beginning from establishment to top of the TQM house, everything is bound by the solid mortar of correspondence. It goes about as a key connection between all components of TQM. Correspondence implies a typical comprehension of thoughts between the sender and the recipient. The achievement of TQM requests correspondence with and among all the association individuals, providers, and clients. Managers must keep open aviation routes where representatives can send and get data about the TQM procedure. Correspondence combined with the sharing of right data is fundamental. For correspondence to be trustworthy the message must be clear and the collector must decipher in the way the sender planned. There are diverse methods for correspondence, for example,

\subsubsection{Descending Correspondence}

This is the predominant type of correspondence in an association. Introductions and talks fundamentally do it. By this, the directors can make the representatives clear about TQM.

\subsubsection{Upward Correspondence}

By this, the lower level of workers can give recommendations to the upper administration of the impacts of TQM. As representatives give knowledge and productive feedback, directors must listen adequately to revise the circumstance that comes to fruition using TQM. This structures a level of trust amongst bosses and workers. This is additionally like enabling correspondence, where directors keep open ears and tune into others. Sideways correspondence - This kind of correspondence is essential since it separates obstructions between offices. It likewise permits managing clients and providers in a more expert way.

\subsection{Roof}

Recognition is the last and last component in the whole framework. It ought to be accommodated both proposals and accomplishments for groups and in addition people. Workers endeavor to get acknowledgment for themselves and their groups. Identifying and perceiving patrons is the most essential employment of a boss. As individuals are perceived, there can be immense changes in confidence, profitability, quality and the measure of exertion urged to the main job. Acknowledgment comes in its best frame when it is instantly taking after an activity that a representative has performed. Acknowledgment comes in various ways, places and time, for example,

\subsection{Ways}

It can be by method for the individual letter from top administration. Additionally by honor dinners, plaques, trophies and so forth. Places - Good entertainers can be perceived before offices, on execution sheets and furthermore before top administration. Time - Recognition can be given whenever like in workforce conference, yearly honor feasts, and so on. (The Eight Elements of TQM", 2017)

\subsection{Appreciation for a System}

A leader must comprehend the framework he or she is endeavoring to oversee. Without this understanding, the framework can not be overseen or made strides. A framework can't comprehend itself or oversee itself. Enhancement of the parts does not advance the entirety. Framework enhancement requires coordination and collaboration of the parts which requires administration.

\subsection{A Good Team Knows Why It Exists}

It's insufficient to state, "We're the 6th grade group of instructors," that is basically what characterizes (you educate a similar review) however not why you exist. A reason for being is a group may be: "We meet up as a group to bolster each other, gain from each other, and distinguish ways we can better address the issues of our 6th grade understudies." Call it a reason or a mission - doesn't generally make a difference. What is important is that the individuals who go to never feel like they're quite recently committed to go to "another meeting." The reason for existing is pertinent, significant, and clear.

\subsection{A Good Team Creates a Space for Learning}

There are many purposes behind which those of us working in schools may accumulate in a group yet I trust that those reasons ought to contain open doors for taking in with and from each other. I have met not very many instructors who would prefer not to learn. We're an inquisitive cluster and there's such a long way to go regarding instruction. So in a compelling group, learning occurs inside a protected setting. We can commit errors and go out on a limb and ask each and every question we need.

\subsection{In a Good Team, There's Healthy Conflict}

This is unavoidable - and fundamental - in case we're 
adapting together and left on some sort of venture together. We differ about thoughts, there's productive exchange and contradict, and our reasoning is pushed.

\section{(i). Members of a Good Team Trust Each Other}

This implies when there's the inescapable clash, it's overseen. Individuals know each other. We hear each out other. There are understandings about how we treat each other and draw in with each other and we screen these assertions. There's likewise somebody, for example, a facilitator who guarantees this is a protected space. Moreover, with the end goal for there to be trust inside a solid group, we see impartial support among individuals and shared basic leadership. We don't see a replication of the biased examples and structures of our bigger society, (for example, male strength of talk et cetera).

\section{(ii). Finally, a Good Team has a Facilitator, Leader, or Shared Leaders}

There's somebody - or a turn of individuals - who direct the ship. This guarantees there's the sort of deliberateness, arranging, and assistance at the time that is fundamental for a group to be high functioning. (Aguilar, 2017).

\section{Education and Deming's 14 Points}

Every level of the time period we are need some time of command which is called leadership. In the perspective of Ancona et al (2007) have furthermore developed a model of dispersed organization focusing on four capacities: sense making (understanding the setting in which an association and its kinfolk work), relating (building associations inside and transversely finished affiliations), visioning (making a persuading photograph without limits), and coming up with (becoming new ways to deal with fulfill the vision). Spreading over the social and academic, the adjusted what's progressive, natural, connected and imaginative points of confinement they prescribe that it is now and again if, whenever, some individual will be comparatively skilled in each of the four capacities.

\subsection{Deming's 14 Points}

Central to this new management will be the 14 points of W. Edwards Deming, derived from industry and geared toward a program of total quality management

\subsubsection{Deming Point 1 Constancy of Purpose}

Educational programs like business and industry must have a reason and that "explanation behind presence" must be spelled out in a statement of purpose. Going astray from a typical supposition, Deming states that profiting is not the main role of business. Unexpectedly, he says, that remaining in business and enhancing items and administrations ought to be the principle mission.

In a comparable manner "raising test scores" ought not be the essential concentration of schools. Instruction, similar to business, needs to concentrate on its items and administrations. In schools the understudy is both the specialist and also the item and we have to give those administrations that will enable understudies to obtain essential aptitudes and wind up noticeably profitable subjects. The viability of a statement of purpose in coordinating the course of a business or instructive undertaking is straightforwardly needy upon how much the CEO, Superintendent or Principal completely underpins that mission with the representative's simultaneousness. Unless the workers see solid proof of top administration support and association they won't effectively get tied up with the mission. In control hypothesis phrasing, the statement of purpose ought to end up noticeably a piece of the quality universe of all members who will then gage their practices against this acknowledged reason. As far as reality treatment procedures, when we ask people what they need we are essentially searching for their own statement of purpose.

\subsubsection{Deming Point 2 Adopt the New Philosophy}

Quality Approach" must turn into the new theory. Business can at no time in the future live with poor workmanship, terrible materials, grim administration or inadequately prepared representatives. Instruction can't keep on accepting high dropout rates, poor educating and brought down understudy execution. What is required is a change of administration styles from supervisor to lead administration. Educators and heads must get comfortable with control hypothesis and reality treatment keeping in mind the end goal to execute lead administration methods and establishment a quality instruction program.

\subsubsection{Deming Point 3 Cease Dependence on Mass Inspection}

Quality comes not from examination but rather from improvements of the procedure.

In instruction, instructors need to include the understudy as a laborer to assess the nature of his or her work, product or result. At the point when understudies become tied up with the self-assessment handle the nature of their work is enormously upgraded.

Utilizing reality treatment procedures to discover what understudies need and what they are doing to get what they need sets the phase for this procedure of self evaluation.

\subsubsection{Deming Point 4 - End Practice of Awarding Business on Price Tag Alone}

As per Deming, cost has no significance without a measure of the quality being acquired.

In instruction we can refer to various illustrations. At the point when school areas keep up such high class measure midpoints that understudies are coming up short in view of the absence of close supervision, they don't appear to mull over the additional cost it takes for understudies to rehash a class.

\subsubsection{Deming Point 5 Improve Constantly}

In Education, rather than "convenient solution", we ought to be taking a gander at the framework and inspect our objectives and mission. Examination of long and short range 
objectives is an indication that we are starting to concentrate more on enhancing the framework instead of laying more on to understudies i.e. extending the school day, school year and toughening scholarly norms. Remember that change is not an onetime exertion but rather is a progressing procedure in schools and business and industry.

\subsubsection{Deming Point 6 Institute Training/Retraining}

A central point in the supposed "educator burnout disorder" is the absence of sufficient pre-benefit and inadministration preparing that causes instructing the world's hardest occupation - to be a disheartening and as a rule disappointing knowledge. It is sufficiently not to have a statement of purpose. You must be sure people are prepared to complete that mission.

\subsubsection{Deming Point 7 Institute Leadership}

The requirement for a style of initiative that is, for the most part, not found in the current existing industry or instruction. This is called Lead Management - overseeing without intimidation. It is portrayed by four striking elements:

As a matter of first importance, the pioneer must draw in the laborer in a discourse about what should be finished. $\mathrm{He}$ stresses the need for quality work while requesting input from the specialists. He tries to fit the employment to the abilities and necessities of the laborer.

Second, the pioneer, administrator or instructor models what should be done as such that the specialist/understudies comprehend what's in store. Third, a lead director is focused on the idea of self assessment with respect to the specialist with the information that the people taking every necessary step are in the best position to assess the nature of the work. At last, the pioneer is a facilitator whose occupation is to give the specialist a non-coercive atmosphere alongside sufficient apparatuses and direction to do the job. Lead chiefs invest the greater part of their energy chipping away at the framework to enhance the execution of the specialists.

In training, the absolute opposite to lead administration manager administration - is the most incessant style watched. Supervisor administrators set principles, tell as opposed to show how, and depend vigorously on reward and compulsion to control understudies and educators.

\subsubsection{Deming Point 8 Drive out Fear}

Compulsion is the most destructive component in a work put. It decimates profitability and quality work. Laborers that dread their managers or bosses may create yet will never accomplish quality. Overseers, principals and instructors who work from a base of intimidation and dread will never incite regard and dedication from those they oversee. Nor will they enhance the nature of work being created. A decent case of the use of dread and pressure in schools is the excess of principles representing understudy conduct. The dialect of the standards are constantly expressed in negative terms "No smoking", "No littering", "Keep off the grass", and so forth. Until instructors acknowledge the way that dread and quality work are inconsistent there can be no upgrades to the instructive framework.

\subsubsection{Deming Point 9 Break down Barriers Between Staff Areas}

Deming says that the greater part of business associations is taking after a supervisor administration base framework which can't cultivate or advance collaboration as compulsion delivers an antagonistic atmosphere which invalidates participation. Whenever, be that as it may, schools operationalize the concepts of lead administration and look for contribution from all staff individuals in the basic leadership handle, the atmosphere will change. At the point when individuals feel that their thoughts, remarks and proposals are esteemed they won't just feel a piece of the group however will build the nature of their execution and work. Schools, who consider themselves to be the encapsulation of majority rule standards, feel that they represent the group approach with everybody functioning as a unit. Those of us who work in schools realize this is not the situation in many occasions. We have just to take a gander at the standing framework that exists in the larger part of government funded schools. As a matter of first importance we have the fundamental certificated/grouped refinement. The principals and instructors consider themselves to be more imperative than the representatives, caretakers and instructional associates. The last gathering, in many cases, feel like peasants particularly in the range of working conditions and pay rates.

\subsubsection{Deming Point 10 Eliminate Slogans, Exhortations, and Targets for the Work Force}

As indicated by Deming, trademarks never helped anybody - they just produce dissatisfaction and hatred. The message that labourers get from organization created mottos is that they could improve on the off chance that they attempted. At the point when confronted with poor lighting, bumbling supervision and defective materials the labourers despite smart urgings essentially presume that administration doesn't comprehend the issues and couldn't care sufficiently less to discover.

At the point when trademarks are produced by as well as with the specialists, they wind up noticeably trustworthy indications of commonly settled upon objectives. In schools we see the capable impact of understudy produced trademarks that periodically go before essential athletic and get-togethers. Since a dominant part of the understudy body needs to win the occasion, the trademarks are just outer images of their inner inspirations.

\subsection{Deming Point 11}

Dispose of Numerical Quotas Work portions sometimes incorporate any hint of a framework that would enable somebody to make a superior showing with regards to. At the point when shares depend on the normal yield of a gathering, the result will be unremarkableness - a large portion of the specialists will be above and half underneath the quantity. Peer weight will hold the upper half to the normal and those 
beneath will be notable meet the models. Schools are infamous for applying weight on instructors to raise test scores. This has prompted proof of tricking and resistance with respect to understudies and educators. This emphasis on a numerical objective has prompted less consideration being paid to those aptitudes that can't be tried by an institutionalized instrument. Rather than measuring individuals by the numbers they turn out it would be much more profitable to set up a framework that cultivates an air of receptivity and acknowledgment for proposals made by the worker

\subsubsection{Deming Point 12 Remove Barriers to Pride of Workmanship}

In Education, much lip administration is given to purported "participative administration rehearses" wherein the representative turns into an indispensable piece of the basic leadership handle. In fact be that as it may, this approach winds up with the worker "taking an interest" and the overseer "overseeing". It's a straightforward discernible maxim that "individuals are anxious to make a decent showing with regards to and bothered when they can't".

\subsubsection{Deming Point 13 Institute a Vigorous Program of Education and Retraining}

Despite the fact that this indicate is comparative number 5 - Institute preparing and retraining - it stresses setting up a complete proceeding with program of instruction that not just prepares labourers in the abilities expected to carry out their occupations however urges them to obtain new information and understanding that sets them up for future assignments. Deming stresses the requirement for labourers to comprehend and utilize fundamental insights to enhance the nature of their items.

In instruction this factual way to deal with investigation and process control means the requirement for the steady assessment of what we are doing. It calls for utilizing both subjective and target methods to gage the adequacy of our instructional procedures rather than "gut level sentiments" or basically reviewing on the likelihood bend.

\subsubsection{Deming Point 14 Take Action to Accomplish the Transformation}

"An excursion of a thousand miles starts by venturing out". That old Chinese maxim abridges the last standard in Deming's 14 point administration handle. When beat administration rolls out a guarantee to improvement its administration style, it must follow up on the premise of this dedication. As indicated by Deming, the principal turning point on an organization's street to quality happens when a "minimum amount" of the representatives comprehend the 14 focuses and end up noticeably dynamic members simultaneously.

\section{TQM and Leadership}

Powerful schools are the results of viable initiative. Whenever principals and instructors concur on their central goal and systematize Deming's 14 focuses, the understudies as labourers and items will receive the rewards of a lead administration system. Leadership in TQM thinking requires a persistent social change and individuals should be guided through the change. Nonstop change can be accomplished through spurred representatives, who work in a group and use profitable apparatuses with the end goal of expanding client's fulfilment.

This authority works for consistent learning, benefit orientated disposition, loaded with constructive vitality and trusts in other individuals of the association on the grounds that TQM is individuals arranged

\section{The Learning Organization}

Learning organizations are spots "where individuals ceaselessly extend their ability to make the outcomes they genuinely seek, where new and sweeping examples of deduction are supported, where aggregate yearning is without set, and where individuals are persistently figuring out how to learn together." (Senge 2006, p. 3)

\subsection{Personal Mastery}

Personal mastery is the teach of consistently reveling further into our own vision, of centering our energies, of creating tolerance, and of seeing reality dispassionately. It is consolidating our own vision with current reality keeping in mind the end goal to settle on better decisions and pick up results.

\subsection{Mental Models}

Mental models are profound established presumptions, speculations, pictures, or pictures that impact our perspective and how we make a move. With mental models it is critical to first take a gander at our own particular suppositions and comprehension of the world. It likewise incorporates the capacity to complete provocative discussions where people uncover their own particular thinking viably, and impact the reasoning of others.

\subsection{Shared Vision}

A feeling of sense of duty regarding a gathering is built up by creating shared pictures without bounds they try to make. At the point when there is honest to goodness vision individuals exceed expectations and learn in light of the fact that they need to, not on the grounds that they are advised to.

\subsection{Team Learning}

At the point when groups are viably learning they are delivering fruitful outcomes, and the individual colleagues are becoming speedier than they could have all alone.

Group learning begins with correspondence (discourse) and the capacity to rest aside presumptions keeping in mind the end goal to take part in a procedure of "aggregate care", and figuring out how to perceive examples of connection that undermine learning. 
On the off chance that groups can not learn, neither can the association.

\subsection{Evolution of Dialogue}

As indicated by Senge and his partners, group discourse moves from start $->$ discussion $->$ pondering. From pondering, the exchange may take after a way to discourse or to suspension and exchange. Group learning urges individuals to consider exchange the "free stream of signifying" joined by sensible examination. (Eisenberg/Goodall, 2010)

\subsection{Systems Thinking}

The individual starts to comprehend that the association is reliant, perceives its connections between key components (i.e. populace, regular assets, nourishment generation) and consistently evolving. Once the individual recognizes this they are equipped for managing the outcomes to the activity or occasion. This train depends on a developing group of hypothesis about the conduct of criticism and unpredictability. It manages the regular events of a framework that prompt development or steadiness after some time.

\section{Leadership and Organizational Effectiveness}

As indicated by Day et al (2001) viable authority was both an exceptionally contextualized and social develop. In investigating the characteristics of these principals the creators recommend that their practices were supported by center individual esteems, for example, regard, reasonableness, correspondence, entirety advancement of understudies and staff, uprightness, and trustworthiness. Day et al (2001) recommend that their qualities and dreams were more good based (devoted to the welfare of staff and understudies) than instrumental (financial). An essential part of authority for these principals were working effectively with individuals and not only a 'work area work' (p.45). Again it is anything but difficult to see likenesses here with the medical attendant pioneer who is devoted to the welfare of staff and patients. Burton et al (2005) completed a contextual analysis investigating the effect of main administration and the general viability of the school. The important has an immediate impact on the viability of the school however some senior administration individuals communicated a longing for expanded self-sufficiency to systematize key procedures all through the school to fabricate initiative limit.

In freedom administration Ruth (2006) underwear that compelling pioneers display what they lecture. They 'walk the discussion' (p.22) so that there is consistency between their qualities, vision, models, and practices. When you contemplate something he will return to you later about it.

\section{Conclusion}

The new logic of Management concentrates on the 14 focuses advanced by W. Edwards Deming, the world's driving specialist on aggregate quality administration. These quality attributes stretch that instructors are for the most part extremely talented and able and that the issue in training lie fundamentally in transit the association is organized and run. What we have to do is to regard instructors as experts, tune in to their recommendations, and urge them to participate in consistent self-change. With this new disposition and alternate components of the new administration theory, it will be conceivable to separate the hindrances inside school associations so that all representatives will be a piece of the group, devoted to the steady quest for instructive quality. EFQM recommends that outcomes concerning execution, clients (patients or understudies), individuals and society are accomplished through initiative. TQM can be an effective instrument in the instructive setting despite the fact that it was created in view of assembling procedures. The key components of a fruitful execution are (1) pick up the support of everybody in the chain of supervision, (2) recognize your clients, (3) concentrate on refining the procedure, and (4) utilize Deming's 14 Focuses as a guide and agenda amid the usage exertion. The last outcome will be a more productive operation and a collaboration mentality instead of a us versus them' state of mind amongst workforce and students. This leadership drives approach and system, which is conveyed through individuals, organizations, assets and procedures. It is outstanding, in the EFQM demonstrate that the weightings connected to the "client" results are the most astounding. On the off chance that we apply this to Class, these outcomes can be depicted in the glad understudy who appreciates going to class and the Exceptional Needs tyke who has the chance to blend with other kids. It shows that initiative is a key empowering agent which accomplishes comes about for the association and these outcomes input to development and learning. In noting the question - is administration basic to driving authoritative viability - I recommend that it is critical to this accomplishment. Nonetheless, it is the manner by which the pioneer leads with regards to the setting which is vital. At the end of the day, it is unrealistic to take an arrangement of general basic achievement elements for an elementary school setting and apply these in disengagement. The qualities, rationality, and ethos of the setting must be to the fore in the estimation of authoritative viability. Utilizing the analogy of the ice sheet where the qualities and theory in the way of life of an association are beneath the water level demonstrates that these results may demonstrate the hardest to quantify. In investigating the pioneer's effect on hierarchical adequacy an exploration approach, for example, a contextual investigation may give some knowledge into these results on the off chance that it is drawn nearer with a receptive outlook. Another method for perceiving the connections amongst administration and hierarchical viability in Education. Moreover, drawing on cases from an alternate setting, for example, training, may support new points of view on these investigations. At last, unique methods for seeing may give us better approaches for knowing, liberating our brains of conventional outlooks and presumptions. 


\section{References}

[1] Ancona D, Malone TW, Orlikowski WJ \& Senge P (2007) In praise of the incomplete leader. Harvard Business Review, February: 92-100.

[2] Aguilar, E. (2017). Effective Teams: The Key to Transforming Schools? Edutopia. Retrieved 5 June 2017, from https://www.edutopia.org/blog/teacher-teams-transformschools-elena-aguilar.

[3] Bradley, Leo H. (1993) Total Quality Management for Schools, Lancaster, Pennsylvania: Technomic Publishing Co., Inc.

[4] Burton N, Brundrett M \& Yeung J (2005) The effective principal: A case study of Management in Education, Ying Wa College, Hong Kong. 19 (4): 28-31.

[5] Deming, W. E. (2000). Out of the crisis (rev. ed.). Cambridge, MA: MIT Press.

[6] Deming, W. E. (1993). The New Economics For Industry, Government \& Education. Cambridge: Massachusetts Institute of Technology Center for Advanced Engineering Study.

[7] Day C, Harris A \& Hadfield M (2001) Challenging the orthodoxy of effective school leadership. International Journal of Leadership in Education, 4 (1): 39-56.

[8] Eisenberg, E. M., GoodallJr, H. L., \& Trethewey, A. (2010).
Organization Communication: Balancing Creativity and Constraint (Sixth ed., pp. 40-232). Boston: Bedford/St. Martin's.

[9] Glasser, W. (1990) The Quality School, New York: Harper and Row.

[10] Napierala, B. (2017). Five important factors in total quality management | About Three. Aboutthree.com. Retrieved 5 June 2017, from http://aboutthree.com/blog/five-important-factorsin-total-quality-management/

[11] Etech. (2017). Principles of Total Quality Management (TQM). Retrieved 5 June 2017, from https://www.etechgs.com/blog/principles-total-qualitymanagement-tqm.

[12] Ruth S (2006) Leadership and liberation. Routledge, London.

[13] Senge, P. (2006). The Fifth Discipline: The Art and Practice of the Learning Organizations. New York: Double Day. Retrieved February 14, 2010.

[14] Steers, R. M. (1977). Organizational Effectiveness: A Behavioral View. Santa Monica: Goodyear Press.

[15] The Eight Elements of TQM. (2017). Isixsigma.com. Retrieved 5 June 2017, from https://www.isixsigma.com/methodology/total-qualitymanagement-tqm/eight-elements-tqm/.

[16] Walton, M. (1986) The Deming Management Method, New York: Putnam Publishing Group. 